\title{
Erratum: Kiselev, I., et al. On the Temporal Stability of Analyte Recognition with an E-Nose Based on a Metal Oxide Sensor Array in Practical Applications. Sensors 2018, 18, 550
}

Ilia Kiselev ${ }^{1, *(\mathbb{D})}$, Victor Sysoev ${ }^{2,3, *(\mathbb{D})}$, Igor Kaikov ${ }^{4}$, Ilona Koronczi ${ }^{5}$, Ruslan Adil Akai Tegin ${ }^{6}$, Jamila Smanalieva ${ }^{6}$, Martin Sommer ${ }^{4}$, Coskan Ilicali ${ }^{6}$ and Michael Hauptmannl ${ }^{1}$

1 Breitmeier Messtechnik GmbH, Englerstr. 27, 76275 Ettlingen, Germany

2 Laboratory of Sensors and Microsystems, Yuri Gagarin State Technical University of Saratov, 77 Polytechnicheskaya str., 410054 Saratov, Russia

3 National University of Science and Technology MISiS, 4 Leninskiy pr., 119991 Moscow, Russia

4 Institute of Microstructure Technology, Karlsruhe Institute of Technology, Hermann-von-Helmholtz-Platz 1, 76344 Eggenstein-Leopoldshafen, Germany

5 Science and Technology of Nanosystems, Karlsruhe Institute of Technology, Hermann-von-Helmholtz-Platz 1, 76344 Eggenstein-Leopoldshafen, Germany

6 Faculty of Engineering, Kyrgyz-Turkish Manas University, Mira Avenue 56, 720044 Bishkek, Kyrgyz Republic

* Correspondence: ilia.v.kiselev@gmail.com (I.K.); vsysoev@sstu.ru (V.S.); Tel.: +49-7243-605758 (I.K.); +7-452-998624 (V.S.)

The authors wish to make the following corrections to this paper [1]:

The labels of curves in Figure 5a are in wrong order. Please replace the following:

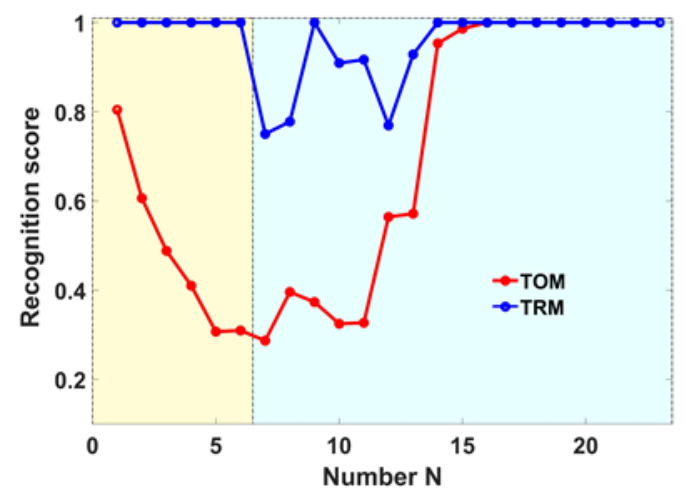

with

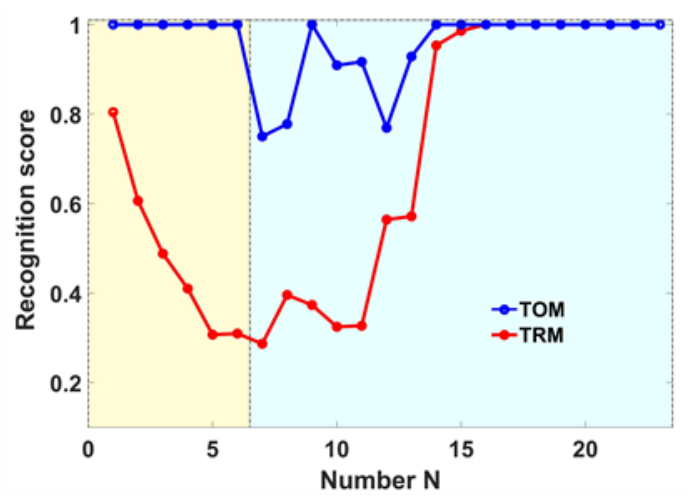


The authors would like to apologize for any inconvenience caused to the readers by this unintentional mistake.

\section{Reference}

1. Kiselev, I.; Sysoev, V.; Kaikov, I.; Koronczi, I.; Adil Akai Tegin, R.; Smanalieva, J.; Sommer, M.; Ilicali, C.; Hauptmannl, M. On the Temporal Stability of Analyte Recognition with an E-Nose Based on a Metal Oxide Sensor Array in Practical Applications. Sensors 2018, 18, 550. [CrossRef]

cc (1)

(C) 2019 by the authors. Licensee MDPI, Basel, Switzerland. This article is an open access article distributed under the terms and conditions of the Creative Commons Attribution

(CC BY) license (http://creativecommons.org/licenses/by/4.0/). 